\title{
A NEW APPROACH TO MEASURING MATERIALISM
}

\author{
Viet Dung Trinh, Curtin University, Australia \\ Ian Phau, Curtin University, Australia
}

\begin{abstract}
This paper presents a different set of mearsurement for materialism based on the theoretical foundation of Richins and Dawson. After various tests, a new 16-item scale was developed to measure four components of materialism, namely material success, material happiness, material essentiality and material distinctiveness.
\end{abstract}

Keywords: Materialism, Scale, Measurement

\section{INTRODUCTION}

The oldest theory that attempted to explain consumers' demand for luxury brands was the theory of conspicuous consumption (Veblen 1890). According to this theory, the demand for luxury brands is motivated by consumers' desires for social status or esteem, which can only be achieved by acquiring and displaying luxury goods and wealth. And thus, there is no surprise that materialism is one of the most popular factors in marketing and consumer research, especially in luxury brands (Faure and Tang 2008, Chaudhuri and Majumdar 2006, Corneo and Oliver 1997). However, materialism - as popular as it is - is still being measured by scales developed over two decades ago while the world has changed intensely. In order to introduce a new approach to measuring materialism, this paper is structured as followed: the second chapter provides an overview of current measurements of materialism and conceptualizing the new scale. Chapter 3 reveals the methodology of scale development. The results from 3 studies are shown in Chapter 4. Chapter 5 concludes the paper with summary and outlook for the new materialism scale.

\section{LITERATURE REVIEW}




\section{Measurements of Materialism}

Many economists see materialism as a value usually refer to "the pursuit of one's own material well-being” (Easterlin and Crimmins 1991) while sociologists describe materialism as a personal value that encompasses concern with material things, competitiveness, and emphasis on making profit as opposed to human well-being (Beutel and Marini 1995). In marketing literature, the two most accepted materialism measurements are from Belk (1985) and Richins and Dawson (1992). Belk (1985) assumes that materialism consists of three traits: possessiveness, nongenerosity, and envy. On the other hand, Richins and Dawson (1992) define materialism as acquisition centrality, acquisition as the pursuit of happiness and possession-defined success. In the last three decades, these two measurements have been employed in so many research for finding indication of materialism in consumer behavior from luxury brands (Zhao and Belk 2002, Belk and Zhou 2001, Corneo and Oliver 1997, Richins and Dawson 1992, Easterlin and Crimmins 1991, Belk 1985) to counterfeit luxury brands (Lu and Lu 2010, Wan et al. 2009, Swami et al. 2009, Furnham and Valgeirsson 2007, Wee et al. 1995). But the two scales have not always been successful in explaining consumer behavior, especially in recent years (Swami et al. 2009, Furnham and Valgeirsson 2007). In a research investigating the non-price determinants of intention to purchase counterfeit goods in Singapore, Belk’s scale to measure materialism traits was adapted but failed the reliability test (Wee et al. 1995). The results from recent attempts using Richin's materialism scale to study materialism in the consumption of counterfeit luxury brands have also showed the inconsistency (Lu and Lu 2010, Wan et al. 2009, Phau et al. 2009, Swami et al. 2009, Furnham and Valgeirsson 2007) and divergence between the 3 
components of the scale (Wan et al. 2009, Swami et al. 2009). All of the mentioned studies had employed the 18-item materialism scale developed by Richins and Dawson (1992) to study materialism as a determinant of the intention to buy counterfeit luxury brands. The scale was able to confirm materialism as a driving factor in Hong Kong (Wan et al. 2009) and Indonesia ( $\mathrm{Lu}$ and $\mathrm{Lu}$ 2010) but failed to deliver a clear answer elsewhere (Phau et al. 2009, Swami et al. 2009, Furnham and Valgeirsson 2007). The scale also faced divergence between its 3 components even when administered in a same demographical area (Swami et al. 2009, Furnham and Valgeirsson 2007).

Belk introduced the materialism traits in the '80s while Richins and Dawson 18 itemscale was introduced in early ' 90 s. Since then, the world has changed dramatically. Friedman (2006) in his infamous book "The World is Flat" mentions about countries, such as those from old Soviet bloc's, are now opening up their market and become emerging markets. When these markets converged with the rest of the globalized marketplace, they would not only add brain power or horizontal collaboration but also new characteristics in terms of consumer demands. China for example, has become one the largest market for luxury goods (The Economist, 2011) but what Chinese consumers are demanding is not entirely the same with consumers from the West (KPMG 2008). And thus, a new materialism scale is required to deliver better measurement of materialism of consumers.

\section{Scale Conceptualization}

The materialism scale (Richins and Dawson 1992) provides a good framework for a new scale because it was built based on the idea that materialism is a value that guides the 
conduct of one's life. In a certain way, it has already included Belk’s materialism traits in its three themes, namely material success, material centrality and material happiness.

Material Success measures the extent to which one uses possessions as indicators of success and achievement in life, both in judging oneself and others.

Material Centrality measures the extent to which possessions are placed in the center of one’s life.

Material Happiness measures the extent to which one believes that possessions are critical to satisfaction and well-being in life. (Richins and Dawson 1992)

Though it provided a good definition to understand materialism by divided it into three dimensions, the 18-item scale of Richins and Dawson has concentrated on the conspicuousness and therefore lacked the ability to measure status latent for each dimension. Among the 18 items, there are only 2 items dedicated to study the status latent-Q3 I don't place much emphasis on the amount of material objects people own as a sign of success, and Q4 The things I own say a lot about how well I'm doing in life.

Furthermore, Mason (2001) points out that materialistic people generate social recognition and status from their possessions in order to distinguish themselves from others. Moreover, materialism is often associated with conspicuous consumption, in which consumer satisfaction is derived from audience reaction rather than functionality of the item. In other words, materialistic people are seen to focus on the consumption of “status goods" and unique consumer products (Lynn and Harris 1997), hence the introduction of distinctiveness into the scale.

\section{METHODOLOGY}




\section{Scale Design}

The development of the scale closely followed recommended psychometric scaling procedures (DeVellis 2003). First a convenience sample of 20 consumers was asked to describe the characteristics of materialistic people related to luxury brands usage behavior. Items were then generated from these responses. In addition, items were also generated from previously developed materialism scales and the materialism literature (Atay and Sirgy 2009, Richins and Dawson 1992, Richins 1987, Belk 1985). A pool of 70 items was generated. These items were then screened for ambiguity and reviewed by a panel of experts. The panel consists of marketing academia and professionals. This pool was later trimmed to 47 items, including 18 items from Richins and Dawson (1992), via exploratory factor analysis and reliability analysis. Through a number of other scaling procedures (factor analysis, reliability analysis and validity check) across several samples, a final scale consisting 16 items was developed - with none from the original scale.

\section{The Sample}

A convenience sample of 20 consumers was used for item generation. Three samples of students ( $n=184,89$ and 419) were used to examine the reliability and validity of the scales. All participants are undergraduate business students from a large university in Australia and they participated in the study as part of a course requirement. The final sample consists of students from Australia and oversea campuses, including Hong Kong, Malaysia, Singapore and Mauritius. 60 percent of the respondents were female and almost 90 percent were under 25 years old. 


\section{RESULTS}

The 16 items of Materialism Scale were subjected to exploratory factor analysis (EFA) using SPSS version 19. Prior to performing the EFA, the suitability of data for factor analysis was assessed. In all samples, inspection of the correlation matrix revealed the presence of many coefficients of .3 and above. The Kaiser Meyer-Olkin value s for the three samples were $.775, .817$ and .860 , exceeding the recommended value of .6 (Kaiser 1970, 1974) and Bartlett's Test of Sphericity (Bartlett 1954) reached statistical significance supporting the factorability of the correlation matrix.

EFA and reliability analysis revealed the presence of four factors with eigenvalues exceeding 1 . An inspection of the scree plot also supported the four-factor solution by showing a clear break after the fourth component (Catell 1996). To aid in the interpretation of these four factors, Varimax rotation was performed. The rotated component matrix for the 3 samples is shown in Table 1. Based on the result, four factors are namely Material Success, Material Happiness, Material Essentiality and Material Distinctiveness. Rather than measuring the extent to which possessions are placed in the center of one's life like Material Centrality, Material Essentiality is the belief that possessions are essential and responsible for everything in one’s life. And Material Distinctiveness measures the extent to which one uses possessions as a device to stand out of the crowd.

Over the 3 samples, coefficient alpha estimates for the factors ranged from .863 to .906 for the success factor, from .813 to .859 for the happiness factor, from .824 to .969 for the essentiality, and .732 to .900 for the distinctiveness factor. Alpha for the overall 16-item 
scale ranged between .849 and .910. In short, the Cronbach's alpha value are all well above the recommend criterion of 0.7 (Pallant 2000), providing strong evidence for internal consistency of the scales.

The 18 items from original scale were included in the final test but none of them made it to the final scale. These items were removed due to low inter-item correlation (alpha for material success, material happiness and material centrality was .574, .456, and .476 respectively) and cross-loading (see Table 2).

\section{CONCLUSION}

Richins and Dawson’ materialism scale (1992) has provided a good measurement of materialism in marketing and consumer research, especially those involved in luxury brands and related, for over two decades. But the world market has changed dramatically since then and it requires a different measurement to capture materialism. After reliability and validity assessments, the new 16-item materialism scale has been proved to be in good standard and will provide reliable results. The main difference between the new 16-item materialism scale and the original 18-item scale is the approach to measure materialism. The new scale measures not only conspicuous latent but also status latent and distinctiveness.

The main limitation of this research is the use of student samples. There are many other age groups that are absent in the research because of the samples. But again, this would not be expected to alter the obtained results because it was a development phase. Future research using the new scale to measure materialism of consumers is recommended. 
Nevertheless, the new materialism scale does not only answer the gap of contribute the marketing literature but also add valuable insights for luxury brands management. Further research into this subject will help luxury brands with better understanding of what drive consumers toward their brands so they can come up with more effective strategies and designs. As suggested by previous literature, materialism also holds a vital key to understand the consumption of counterfeit luxury brands. By understand the material values consumers see in counterfeit luxury brands, companies would be able to form a more effective strategy to curb the trade of counterfeit luxury brands.

\section{REFERENCES}

Atay E.G. and Sirgy J. 2009, “Developing a new measure of materialism”, Advances in Consumer Research Asia Pacific Conference Proceeding, Vol 35, 907.

Bartlett M.S. 1954. A note on the multiplying factors for various chi square approximations. Journal of the Royal Statistical Society, 16, 296-298.

Belk R. and Zhou N. 2001. A reader response analysis of global and local appeals Chinese advertising, Salt Lake City Utah: Odyssey Films (21 minutes video).

Belk, R.W. 1985. Materialism: trait aspects of living in a material world. Journal of Consumer Research 12, 265 - 280.

Beutel, A.M. and Marini, M.M. 1995. Genders and values. American Sociological Review 60, 436 - 448.

Catell R.B. 1966. The scree test for number of factors. Multivariate Behavioural Research, 1, 245-276.

Chaudhuri H.R. and Majumdar S. 2006. Of Diamonds and Desires: Understanding Conspicuous Consumption from Contemporary Marketing Perspective, Academy of Marketing Review, 2006 (11), 2-18.

Corneo G. and Olivier J. 1997. Conspicuous Consumption, Snobbism and Conformism, Journal of Public Economics, 66(Oct), 55-71.

DeVellis, R.F. 2003. Scale Development: Theory and Application, 2nd . Newbury Park, Sage. 
Easterlin, R.A. and Crimmins, E.M. 1991. Private materialism, personal self-fulfilment, family life and public interest: the nature, effects, and causes of recent changes in the values of American youth. Public Opinion Quarterly 55, 499 - 533.

Eastman, J.K, Goldsmith, R.E and Flynn, L.R. 1999. Status Consumption in Consumer Behavior: Scale Development and Validation. Journal of Marketing Theory and Practice 7 (3), 41-52.

Faure G. O. and Fang T. 2008. Changing Chinese values: Keeping up with paradoxes, International Business Review, 17, 194-207.

Friedman T. 2006, The World is Flat, Farrar, Straus and Giroux.

Furnham, A., and Valgeirsson, H. 2007. The effect of life values and materialism on buying counterfeit products. Journal of Socio-Economics 36 (5), 677-685.

Kaiser H. 1970. A second generation Little Jiffy. Psychometrika, 35, 401-415.

Kaiser H. 1974. An index of factorial simplicity. Psychometrika, 39, 31-36.

KPMG, 2008, China's Luxury Consumers: Moving up the Curve, available at http://www.kpmg.com.hk/.

Lu L.C. and Lu C.J. 2010 Moral Philosophy, Materialism and Consumer Ethics: An Exploratory Study in Indonesia, Journal of Business Ethics, 94, 193-210.

Lynn, M. and Harris, J. 1997. The desire for unique consumer products: a new individual differences scale. Psychological Marketing 14, 601 - 616.

Mason, R. S. 2001. Conspicuous consumption: A literature review. European Journal of Marketing 18 (3), 26 - 39.

Pallant J. 2000. Development and validation of a scale to measure perceived control of internal states. Journal of Personality Assessment, 75, 2, 308-337.

Phau, I., Sequeria, M. and Dix, S. 2009. To buy or not to buy a 'counterfeit' Ralph Lauren polo shirt. Asia-Pacific Journal of Business Administration 1, 1, 68-80.

Richins, M.L. 1987. Media, Materialism, and Human Happiness. Advances in Consumer Research Vol. 14, 352-356.

Richins, M.L. and Dawson, S. 1992. A consumer values orientation for materialism and its measurement: scale development and validation. Journal of Consumer Research 19, $303-316$. 
Swami V., Chamorro-Premuzic T., Furnham A. 2009. Faking it: Personality and individual difference predictors of willingness to buy counterfeit goods, The Journal of Socio-Economics, 38, 820-825.

The Economist, 2011, The Middle Blingdom, published on 17 Feb 2011, available at http://www.economist.com/node/18184466

Tom, G., Garibaldi, B., Zeng, Y., Pilcher, J. 1998. Consumer demand for counterfeit brands. Psychology and Marketing 15, 405-421.

Veblen, T. 1899, The theory of the leisure class, Dover Publications, New York.

Wan W.W.N., Luk C.L., Yau O.H.M., Tse A.C.B., Sin L.Y.M., Kwong K.K. and Chow R.P.M. 2009 Do traditional Chinese Cultural Values Nourish a Market for Pirated CDs?, Journal of Business Ethics, 88, 185-196.

Ward, S. and Wackman, D. 1971. Family and media influences on adolescent consumer learning. American Behavioural Scientist 14, 415 - 427.

Wee, C., Tan, S.-J., Cheok, K.-H. 1995. Non-price determinants of intention to purchase counterfeit brands. International Marketing Review 12, 19-47.

Zhao X. and Belk R. 2006. Sinolization: An International Advertising Strategy for China, Journal of Asia Pacific Marketing 1 (1), 3-18. 
TABLES

Table 1. Rotate component matrix

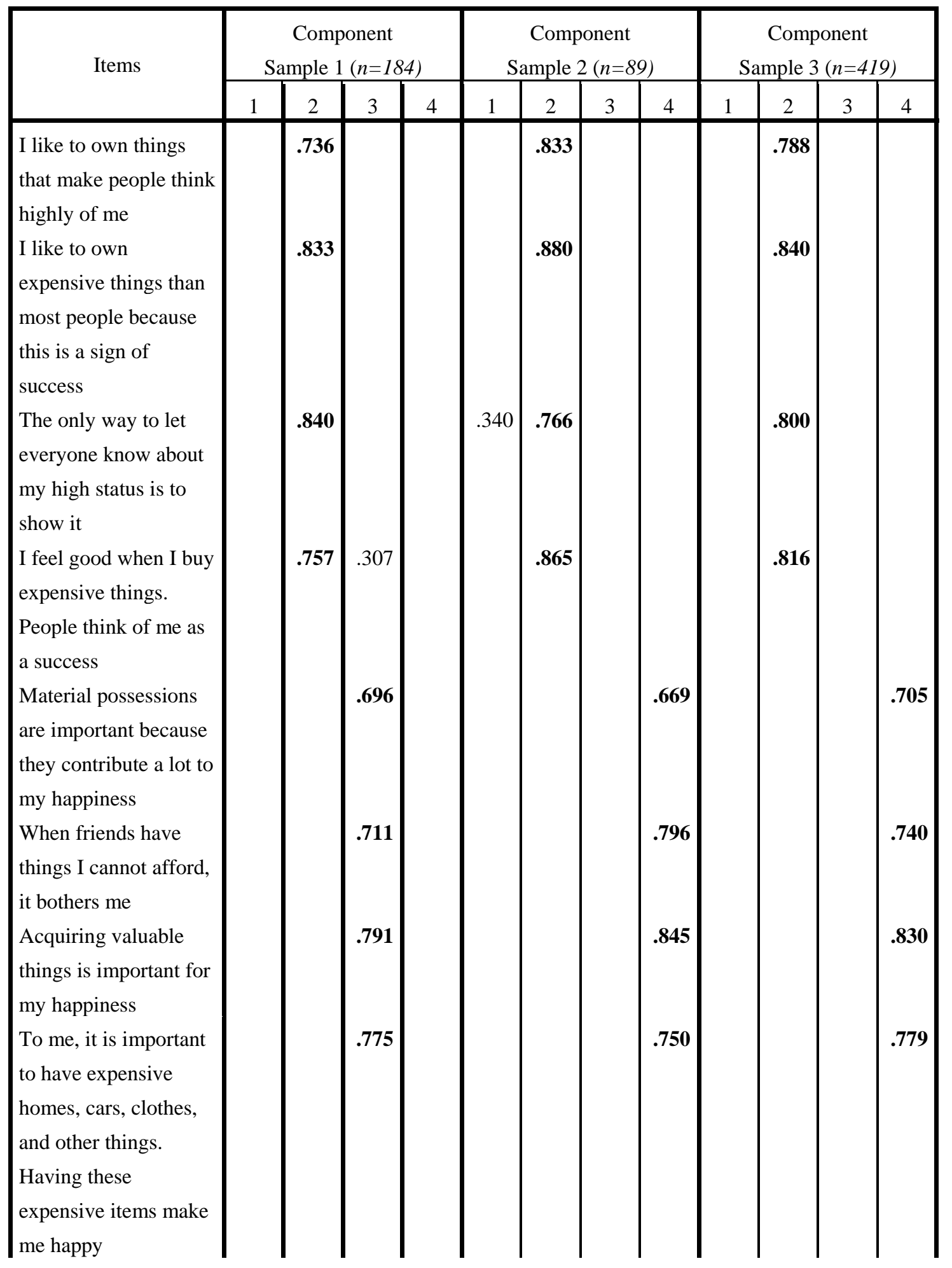




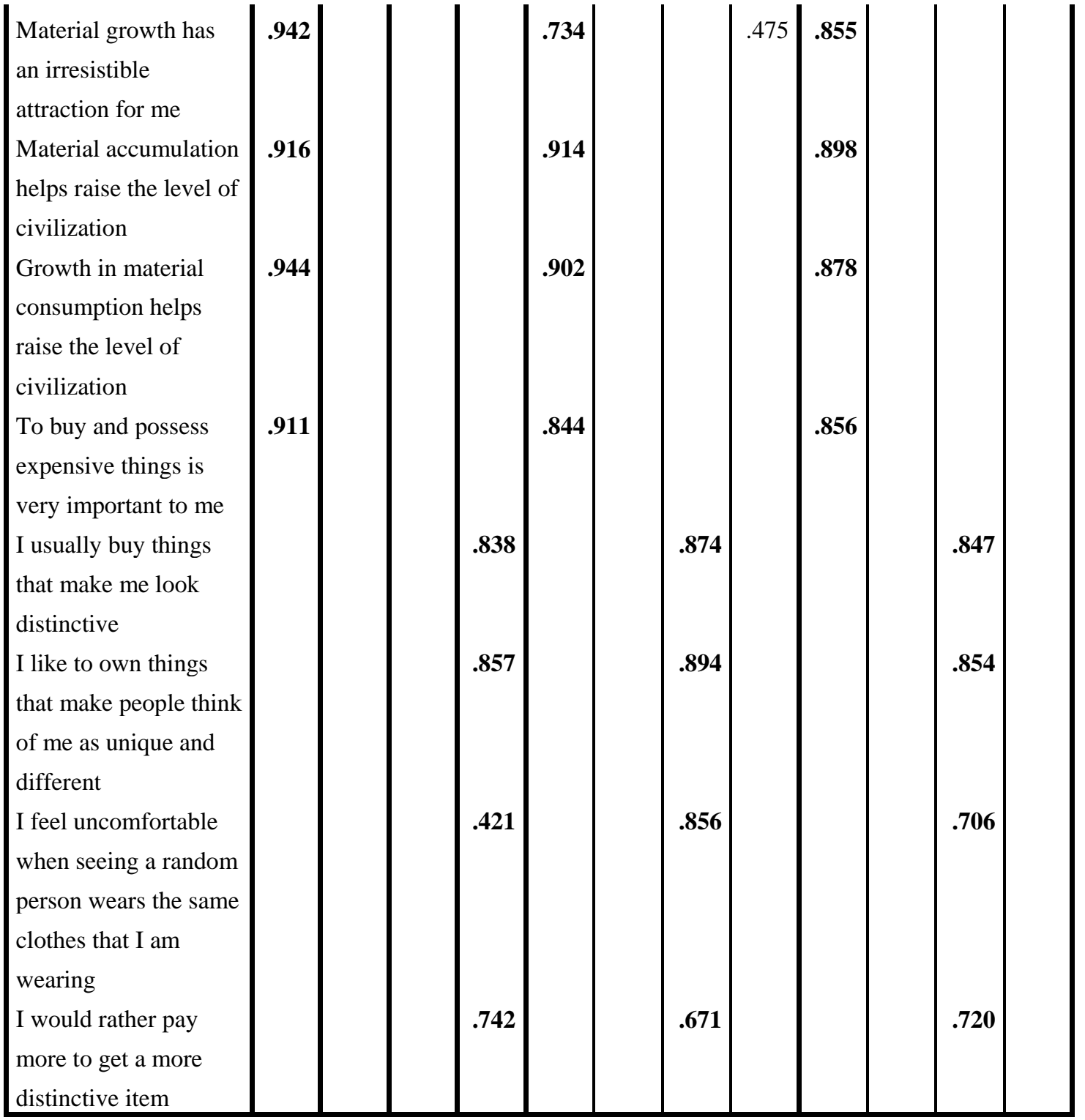

Table 2. Rotate component matrix -original 18-scale item (Richins and Dawson)

\begin{tabular}{|c|c|c|c|c|c|}
\hline & \multicolumn{5}{|c|}{ Component $(n=419)$} \\
\hline & 1 & 2 & 3 & 4 & 5 \\
\hline I admire people who own expensive homes, cars and clothes & .713 & & & & \\
\hline
\end{tabular}


Some of the most important achievement in life include acquiring material possessions

I do not place much emphasis on the amount of material objects people own as a sign of success

The things I own say a lot about how well I am doing in life

I like to own things that impress people

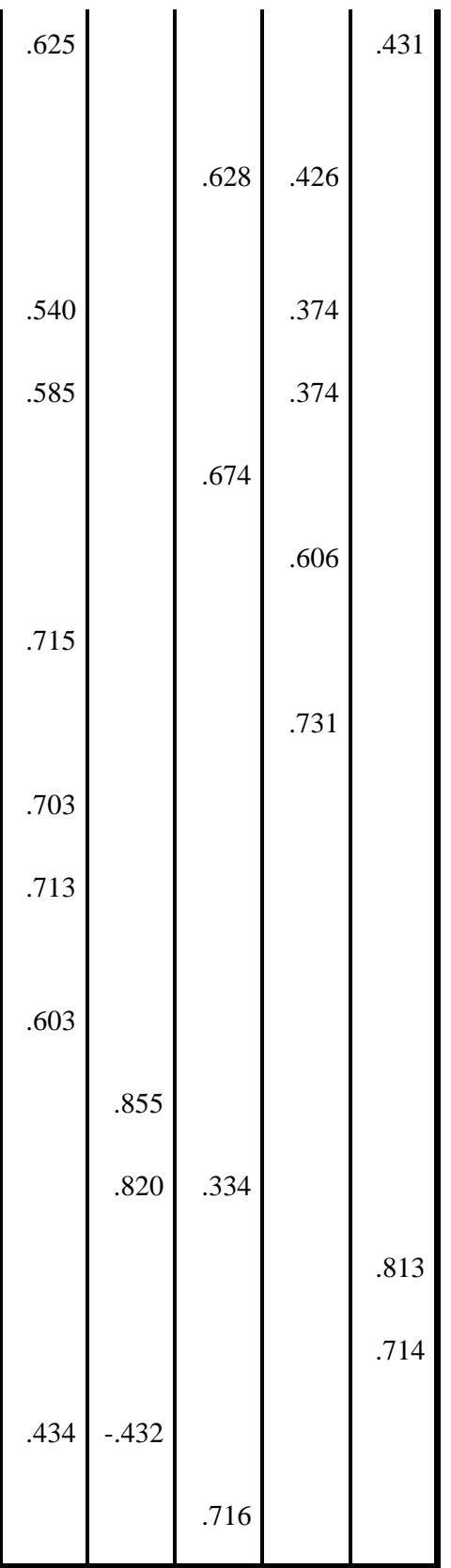

I put less emphasis on material things than most people I know 